\title{
SUSTAINABLE AND RESILIENT COASTAL CITIES: TRIGGER TO ENHANCE NATURE-BASED SOLUTIONS TO CLIMATE CHANGE/SEA LEVEL RISE - THE BELGIAN CASE
}

\author{
PATRICK DE KLERCK ${ }^{1} \&$ NEIL HOSKINS ${ }^{2}$ \\ ${ }^{1}$ Department of Environment, Flemish Government, Belgium \\ ${ }^{2}$ Department for Place, Southend-on-Sea Borough Council, UK
}

\begin{abstract}
One of the geographical areas where the effects of climate change manifests itself clearly is the coastal zone. Cities and municipalities on the coastline assume that the current efforts to protect the coast from the impact of climate change in the short and medium term will be sufficient. There is a genuine problem concerning stakeholder awareness and durable partnerships. Apart from the ("imposed") interventions, additional efforts are limited. The measures are primarily aimed at the "sea side" and implemented as grey infrastructure while measures should also be considered in the corresponding urban littoral area. We note that the need to make more use of climate adaptation, for example (fresh) water storage and retention areas, are rarely included in spatial plans and permits. Climate change is, unfortunately, not seen as an opportunity to progress new urban coastal landscapes and spatial innovations. In each of the ten cities and municipalities on the Flemish coastline (northern part of Belgium), there are ongoing projects on climate change adaptation and innovation. Nature based solutions (NBS) are essential when implementing a sustainable and resilient coastal area. These include hard and soft measures to raise the weakest areas of the coastline to a higher safety level, the possible adaptation of the morphological situation at the seaside, adaptive and robust town scaping. Due to the uniqueness of the urban zone, area-specific tailoring is preferable. These are the key elements of the INTERREG 2Seas project "Sustainable And Resilient Coastal Cities" (SARCC) in which nature based solutions (NBS) are demonstrated.
\end{abstract}

Keywords: resilience, sustainability, pilots, awareness, partnerships, international cooperation, Flemish coast.

\section{INTRODUCTION}

Population densities in coastal regions are much higher than in inland built up areas. However, these cities are particularly at risk of natural hazards. Coastal cities need to quickly prepare for the risks associated with climate change, which further increase their vulnerability to extreme weather events [1]. Therefore, an integrated approach to sustainable and resilient building is necessary [2].

To be resilient, a city must not only overcome environmental hazards but protect and integrate key ecosystem services, as well as develop economic, social and institutional resilience. As part of the adaptation and mitigation efforts to address environmental challenges, the city should work on increasing the adaptive capacity of buildings and critical infrastructure [3]. To allow for this, the system would need an institutional set up that allows for participation, as well as an urban risk assessment and a robust decision-making process that is based on cost-benefit assessments valuing social, economic and environmental aspects and considers risk and a longer time horizon [4]. Community engagement and improved social participation are essential to build local resilience and reducing risk by providing bonding, bridging, and linking practices that enhance appropriation of neighbourhoods and ecosystems. Organized and knowledgeable communities can better cope with disasters, learn from previous experiences, adapt to new environments and ultimately become more resilient. 
To be effective, urban resilience strategies should incorporate partnerships with other levels of government as well as with other cities. This is the main aim of the recently approved INTERREG 2Seas project SARCC.

\section{LAND-USE PLANNING TOOLS CAN CONTRIBUTE \\ TO RISK MANAGEMENT}

On one hand, land-use planning can be used to favour more compact urban developments that reduce intra-urban trips and commuting times. In turn, such compact arrangements result in lower emissions, less traffic and more productive urban centres. Service levels and nodal value are key elements to reach high-density development.

Coastal cities threatened by sea level rise or sea water intrusion, are turning to land-use planning through regulation or market incentives [5]. In the city of Ostend, a sea level rise of $11.5 \mathrm{~cm}$ was measured between 1953 and 2016. One can prohibit development under a certain threshold and requiring minimum heights in lower floors for all other risk-prone areas in coastal cities. Also, the use of the lower floors can be altered. Within this framework, the possibilities of negotiable urban development rules and multiple land use are to be explored.

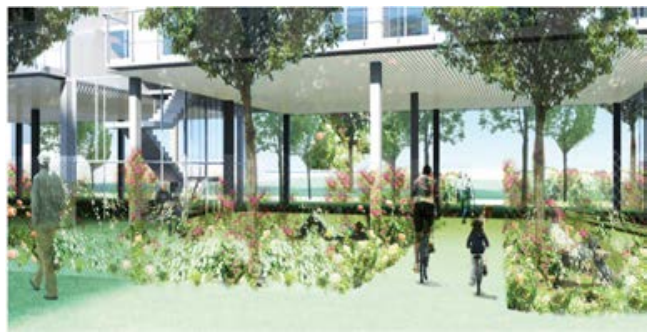

Figure 1: Altering the use of lower floors. Vazal, Chalon-sur-Saône, France.

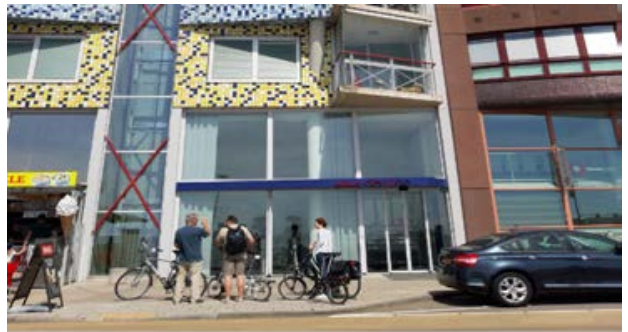

Figure 2: Altering the use of lower floors. Coastal promenade Vlissingen, The Netherlands.

\section{TERRITORIAL DEVELOPMENT PROGRAM FOR THE FLEMISH COAST}

A "Territorial Development Program" (T.OP - Territoriaal Ontwikkelings Programma) is a new instrument in the spatial development policy of the Flemish Government. It is part of the renewal of the Flemish planning system as a result of the preparation of the Spatial Policy Plan for Flanders [6] and the Regional Plan for Sustainable Development of the Brussels Region [7].

The main aim is to bring together relevant stakeholders (public/private) to achieve (a program of) realizations in the short and medium term in a certain area based on common objectives. The "Departement Omgeving", the Flemish Department for "Environment, Spatial Planning and Development, Energy and Climate" coordinates three T.OPs for the regions Central Limburg in the East of Flanders, the Northern Rim of the Brussels region and the Coastal Zone.

The T.OP Coastal Zone is an innovative spatial development program for the coastal management of the Flemish coastal region. The coastal zone is a dynamic area with major challenges in terms of climate, living, working, mobility, energy, water, recreation, biodiversity, agriculture. 
There are numerous projects, visions, ideas with many governments and partners involved. Different initiatives overlap or influence each other. Tuning is necessary.

That is why the Department "Omgeving" started a Territorial Development Program (T.OP) for the area and signed a cooperation agreement with the province of West Flanders. Together, both governments are working on an action-oriented program for the spatial development of the coastal zone in the short and medium term. Together with all stakeholders and local authorities, the Flemish and the provincial governments will cooperate constructively on themes such as urban reconversion, salinization, spatial quality, sustainability, climate change, mitigation and adaptation.

In addition to the ten Flemish coastal municipalities, the project area also includes nine cities and municipalities from the hinterland, which are mainly occupied by "the Polders". After all, the sea, the beach, the dunes and the polders form a geomorphological entity. Many of the bottlenecks and opportunities manifest themselves in this wider environment.

T.OP Coastal Zone can build on the knowledge gained from several studies and partnership.

The study "Metropolitan Coastal Landscape 2100" developed building suggestions for the long-term for a sustainable coastal region through research by design. The "CcASPARstudy" provided information concerning a climate change adaptive coast and hinterland using the old landscape of dykes and polders and a recent study of the coastal cities brought new insights on future reconversion of the urban environment [8]. The knowledge gained from T.OP Coastal Zone can therefore fully be used in substantiating the approved SARCC project.

\section{SUSTAINABLE AND RESILIENT COASTAL CITIES (SARCC)}

The overall objective of the recently approved INTERREG 2Seas project "Sustainable And Resilient Coastal Cities" (SARCC) is to build the capacity of coastal communities within the 2Seas region to deploy and integrate Nature Based Solutions (NBS) into urban landscapes, existing grey infrastructure and flood defences, making use of the natural adaptive capacity of the coastal system to enhance climate resilience to coastal flooding.

SARCC will develop the understanding of urban leaders, decision-makers and those involved in coastal flood protection, of how they can benefit from using NBS to mitigate future risk and reduce economic damages that result directly from coastal flooding. Essentially, the project embeds new techniques, methodologies and practices into planning guidelines, mobilizing a greater uptake of NBS in coastal defence plans across the 2 Seas area. City partners provide input based on their experiences of delivering the pilot investments and approval processes etc. Knowledge partners utilize their expertise on scientific, historical and technical details to input into the capacity program. During the first Steering Committee (3-4 June 2019/Middelkerke, Belgium) discussions took place on the implementation framework and the monitoring phase, as well about the capacity building program and the visualization/community engagement.

The main outputs are the development of eight pilot projects testing different solutions that demonstrate the benefits of nature-based interventions to build climate resilience to coastal flooding and sea level rise. Without the support of the INTERREG 2Seas program, these pilots would be completed in a traditional "grey" way. The difference that SARCC will make is that NBS would have largely been missed out because they are hard to justify. The SARCC funding allows us to demonstrate what NBS can do and so change the balance of the main implementation.

The approval of the SARCC program provided a "trigger" for the development of sustainable and resilient new projects, as well as the possibility to exchange knowledge 
between different countries, institutions and stakeholders. The knowledge partners are the Marine Archaeological Trust (UK), the Environment Agency/Flood and Coastal Risk Management (UK), Exo Environmental (UK), Tu Delft/Faculty of Architecture and the Built Environment (NL), HZ, University of the Applied Sciences (NL), Regional Council of Hautsde-France/Flood and Coastal Risk Management (FR), Flemish Government - Territorial Development Program for the Coastal Region (BE), Flemish Government/Flemish Agency for Maritime Services and Coast (BE) and VIVES High School/Department IW\&T (BE).

The pilots are located in Middelkerke, Ostend and Blankenberge (Belgium), Gravelines (France), Vlissingen (The Netherlands) and Southend-on-Sea (United Kingdom). New strategies will be adopted by local authorities/partners detailing how NBS can be integrated into flood defence plans. Also, a training and capacity building program for stakeholders is elaborated, to understand how to mobilise NBS into flood defences. In addition, a visualisation toolkit demonstrating these solutions in practice is created making use of best practice, historic trend analysis and adaptive development techniques. Finally, an implementation framework for urban leaders and decision-makers is being drawn out. It is very important the demonstration projects will influence the final approach taken by Flanders in order to deal with climate change and sea level rise.

In order to achieve the addressed outputs, six work packages are established (WP1: Monitoring and Evaluation; WP2: Urban Leaders Capacity Building; WP3: Visualisation and Community Engagement; WP4: Project Management; WP5: Communications and Dissemination; WP6: Pilot projects.

\section{SARCC: WORK PACKAGE 2 : URBAN LEADERS CAPACITY BUILDING}

T.OP Coastal Zone is in charge of work package 2: Urban Leaders Capacity Building. Strong leadership and consistency of approach, policy-level support, cross-disciplinary linkages, analysis and quantification of impacts, committed personnel and availability of technical skills are needed to further develop resilience in the coastal region in a sustainable way.

A resilient city is run by an inclusive, competent and accountable local government that is concerned about sustainable urbanization committing the necessary resources to develop capacities to manage and organize itself before, during and after a natural hazard event. People need to be empowered and encouraged to participate, decide and plan their city together with local authorities (policy co-creation). Local authorities and inhabitants in resilient cities understand the possible risks and develop a shared, local information base on disaster losses, hazards and risks, including who is exposed and who is vulnerable [9].

Within SARCC, the partners co-design and co-create a capacity building program to provide urban authority leaders, key stakeholders and officers that work on coastal flood defences and adaptation (engineers, strategic planners, emergency planners, economic development advisors, designers, etc) with the necessary skills and capacities to understand how they can integrate (and fund) NBS solutions into the coastal flood defence systems of urban areas.

Capacity building for effective, sustainable and equitable urban coastal development is part of a paradigm embracing the principles of "local democracy", "good governance", "transparency", "accountability" and "empowerment", "enabling" and "partnerships" that has underpinned conceptual and practical approaches to urban coastal development policies, planning and management. Empowerment for the governance and management of cities and settlements is about subsidiarity - recognising and giving responsibility to the most effective (most immediate or local) level of authority.

Enabling is about ensuring that those who are empowered have the capacity (information, technology, skills and support) to exercise their authority (power) responsibly and 
effectively. A bespoke program of workshops will be delivered in Belgium, France, the Netherlands and the United Kingdom with the content being created as a direct result of the activities conducted in the other WP's (e.g. how to engage with communities to obtain their support for NBS in WP2). Observer Partners are also invited to participate.

The initial purpose of the workshops is to build participants understanding of why these kinds of solutions are required. It will cover:

- Scientific evidence of sea level rise and climate change and how it will impact urban coastlines and coastal infrastructures.

- Historical trends of coastal flooding in the 2Seas region, highlighting issues with heavy engineering/grey infrastructure solutions.

- Information about nature-based solutions and how they can be used by urban stakeholders to build greater and more adaptable climate resilience measures to coastal flood risk.

A second phase of workshops is developed by the partners that demonstrates how they can utilize the tools that are created through SARCC and understand how they can justify the costs of the investment and approve the use of NBS to build climate resilience to coastal flooding.

- Technical solutions.

- Finance models that demonstrate the business case and added value of NBS in comparison to traditional grey infrastructure.

- How to engage with local communities that will be impacted by the investments (WP3).

All partners are involved in developing the content for this WP:

- City partners provide input based on their experiences of delivering the pilot investments and approval processes etc.

- Knowledge partners utilize their expertise on scientific, historical and technical details as input for the capacity building program.

\section{SARCC: THE FLEMISH PILOTS}

The Flemish pilots are situated in a densely urbanized region, that is insufficiently protected against coastal flooding and the impact of sea level rise: the city of Ostend, area of Mariakerke and Raversijde, the town of Middelkerke and the city of Blankenberge. The pilots will show how more traditional coastal protection measures, the so-called "hard measures", like seawalls are combined with "soft measures", Nature Based Solutions. The coastal protection schemes will be elaborated so coastal protection works can provide a safe, sustainable coastal area that fulfils also the local demands of residents, tourists and other stakeholders. These pilots have the same main goals and are innovative in the use of NBS on the Flemish Coast, yet the coastal protection schemes will be implemented differently.

The pilot in Middelkerke provides a solution for the challenges along the coastline. Coastal protection together with sea level rise and architectural demands, provide specific conditions. Here, a combination of a dense centre zone next to a residential area demands a tailor-made answer. In the centre zone, a wave-stilling basin forms a future proof solution with a touristic added value. In the residential part, a "dune in front of dike" proposal was chosen for its resiliency and attractiveness. This pilot aims to gain experience with both infrastructures, not only the design and execution, but also the maintenance and cross-impact on one another. 


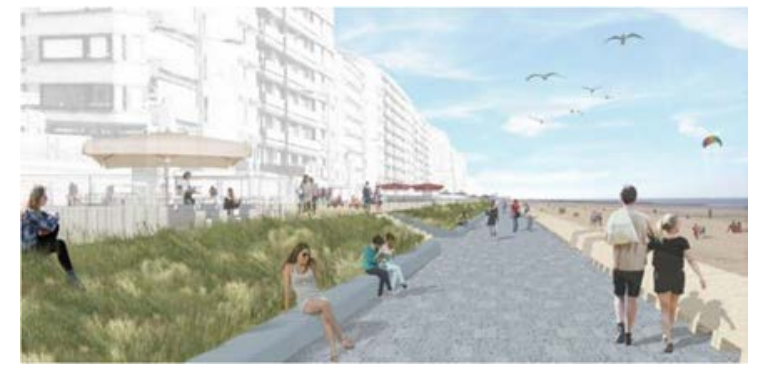

Figure 3: Flood measures in Middelkerke. Stilling wave basin. (Source: Flemish Agency for Maritime Services and Coast/city of Middelkerke.)

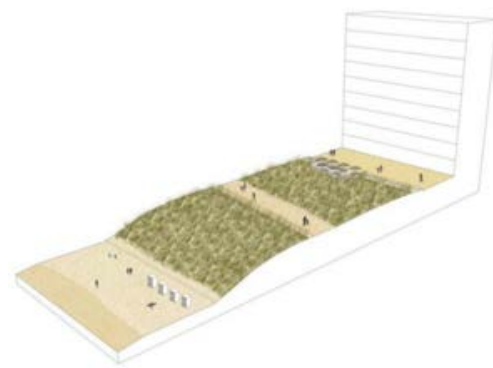

Figure 4: Flood measures in Middelkerke. "Dune in front of dike" proposal. (Source: Flemish Agency for Maritime Services and Coast/city of Middelkerke.)

In Ostend, several problems are tackled. First of all, the coastal protection against severe storm surges and future durability against sea level rise. Secondly, the chosen proposals must be adapted to the local demands and constrains such as tourism, cultural heritage and architectural requirements. Aeolian sand deposit along the coastline and the adjacent roads and railways is a hot political topic, causing long delays for the coastal tram system. The pilot
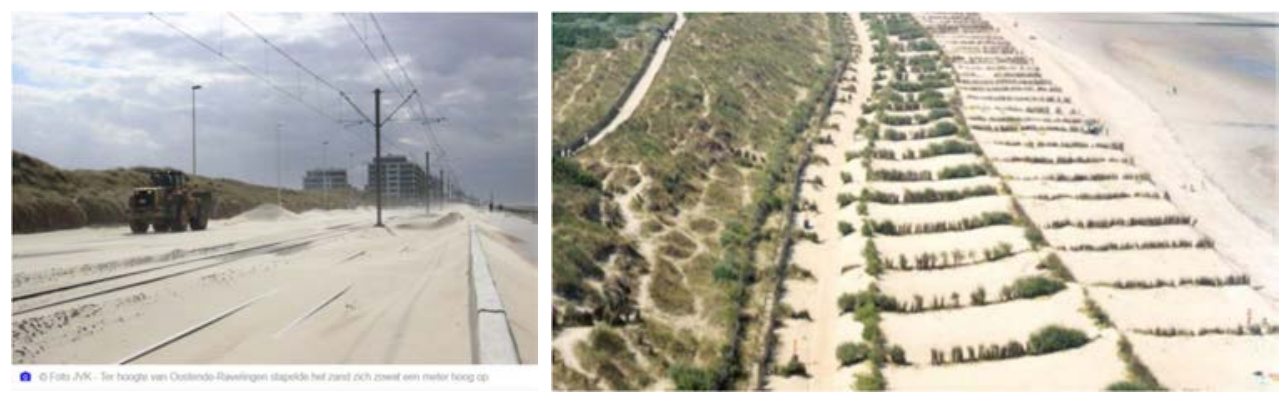

Figure 5: Flood measures in Ostend. Figure 6: Flood measures in Ostend. New dunes to Excessive aeolian sand transport on adjacent roads and railways. (Source: reduce excessive aeolian sand transport. (Source: Flemish Agency for Maritime Flemish Agency for Services and Coast/city of Ostend.)

Maritime Services and

Coast/city of Ostend.)

project elaborates several solutions, combined in one coastal section. The interaction between the distinct zones and design of the adaptive dune as a sand buffer, is investigated in practice.

In the coastal city of Blankenberge, two pilots are planned. On the one hand NBS in a densely urbanized area will be realized between Blankenberge and Zeebrugge: a combination of different types of coastal defence solutions (beach nourishment, dune defence systems, vegetation accretion, reducing excessive aeolian sand transport). 

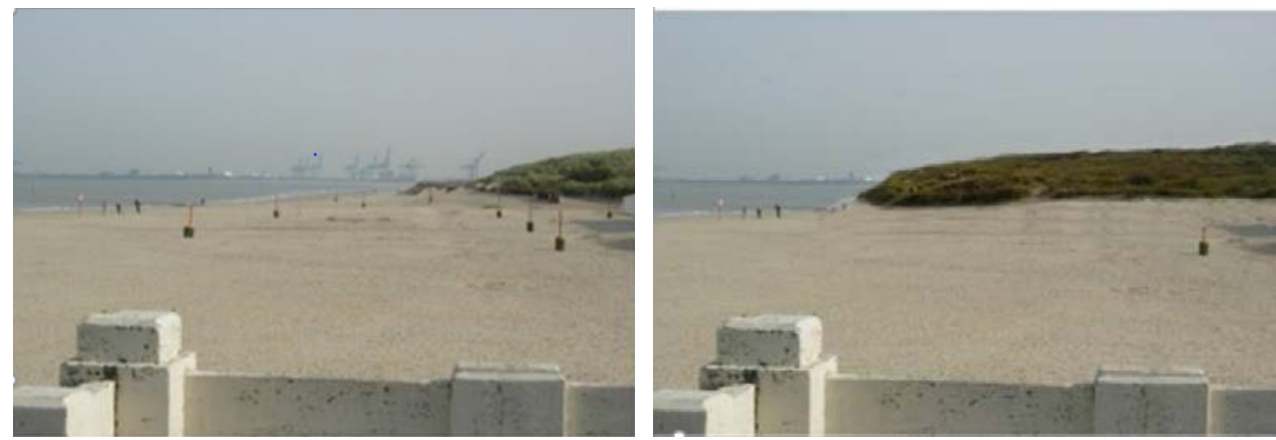

Figure 7: Flood measures in Blankenberge. Figure 8: Flood measures in Blankenberge. Current situation before dune nourishment and vegetation accretion. (Source: City of Blankenberge, 2019.)

Possible situation after dune nourishment and vegetation accretion. (Source: City of Blankenberge, 2019.)

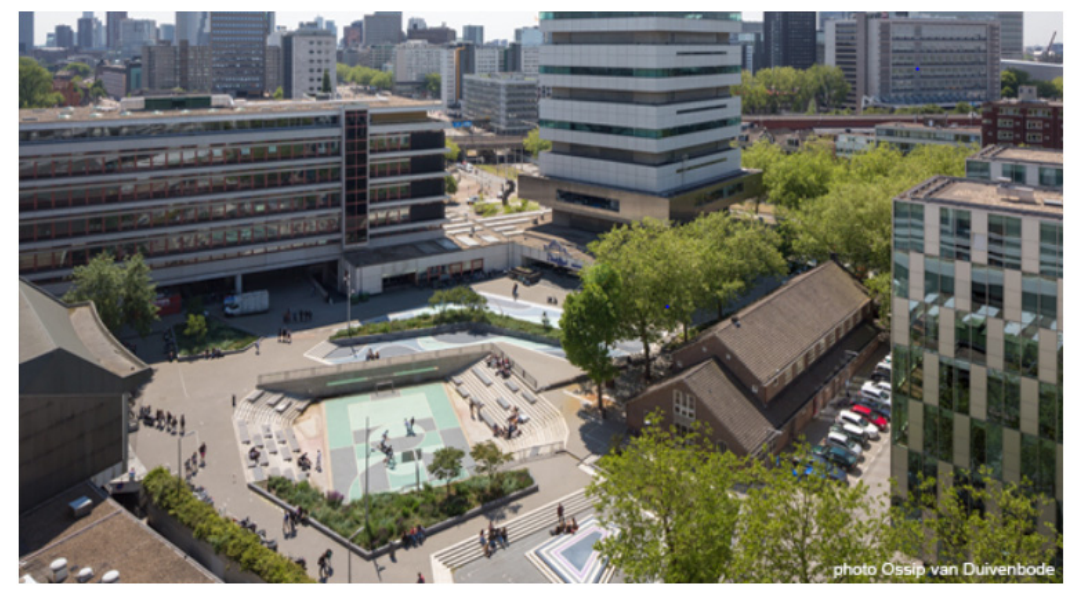

Figure 9: Example of climate adaptive building in Rotterdam with a retention area. (Source: Water Square Benthemplein Rotterdam Climate Initiative, City of Rotterdam supported by the Waterboard Schieland and Krimpenerwaard, 2017.)

On the other hand, an innovative project concerning climate adaptive and resilient building will be constructed on the sea dike and second urban line. Implementation elements are retention areas, upgrading coastal heritage, creating vistas, and using the principles of circular building. Climate change and the use of materials are closely linked [10]. Global use of materials is accelerating. It has more than tripled since 1970 and could double again by 2050 without action, according to the UN International Resource Panel [11].

Rapid urbanization is driving a massive building boom, the challenge is to adopt building practices which minimize the use of raw materials and consequent emissions. Fundamental 
principles of a circular built environment include: financing and investment decisions which recognize the long-term and future value of built assets, reusing existing building materials, modular design of new building materials to allow for re-use and re-assembly, alternatives to carbon-intensive materials such as cement, optimizing the lifetime of buildings and designing them for flexible use.

\section{REFERENCES}

[1] De Klerck, P., Must there still be sand? Adapt for Life, Report of the think tank climate adaptation Flanders 2015-2017, eds L. Boelens, G. Allaert \& C. Walot, Planning UA: Groningen, pp. 77-94, 2017.

[2] Alterre BUUR \& Bureau for Urbanism (eds), Metropolitan Coastal Landscape 2100: Exploratory and Methodological Analysis of the Belgian Coast, Department of Mobility and Public Works: Brussels, pp. 45-49, 2013.

[3] Tractebel, FABRICations \& H + N + S, Urban Coastal System? Department of the Environment, Public Waste Agency of Flanders, Team Flemish Builder, Province of West Flanders: Brussels, pp. 23-38, 2017.

[4] Cloutier, G., Joerin, F., Dubois, C., Labarthe, M., Legay, C. \& Viens, D., Planning adaptation based on local actors' knowledge and participation: A climate governance experiment. Climate Policy, 15(4), pp. 458-474, 2014.

[5] Lipiec, E. et al., Mapping out climate change: Assessing how coastal communities adapt using alternative future scenarios. Journal of Coastal Research, 34(5), pp. 11961208, 2018.

[6] Department of Environment and Spatial Development, Visions and Concepts for the Spatial Policy Plan of Flanders, II The Long Term: 'Uncertainty and Governance'/Radical decentralisation, Flemish Government: Brussels, 2017.

[7] Brussels Region, The Regional Sustainable Development Plan (PRDD: A Strategic Document Based on Medium- and Long-Term Economic, Social, Environmental and Mobility Needs, Brussels, 2018.

[8] Agency for Innovation, Science and Technology, CcASPAR: Climate Change and Changes in Spatial Structures, Strategic Basic Research Project (SBO): Brussels, 2017.

[9] Rodin, J., Valuing the Resilience Dividend, The Rockefeller Foundation: Philadelphia, pp. 12-13, 2017.

[10] de Wit, M., Verstraeten-Jochemsen, J., Hoogzaad, J. \& Kubbinga, B. (eds), The Circularity Gap Report: Closing the Circularity Gap in a 9\% World, Platform for Accelerating the Circular Economy (PACE): The Hague, 2019.

[11] Swilling, M., Robinson, B., Marvin, S. \& Hodson, E. (eds), City-level decoupling urban resource flows and the governance of infrastructure transitions. A report of the Working Group on Cities of the International Resource Panel, UNEP, 2013. 